\title{
A ARTICULAÇÃO ENTRE OS UNIVERSOS LOCAL E GLOBAL NA FORMAÇÃO DO LEITOR
}

\author{
THE ARTICULATION BETWEEN LOCAL AND DISTANT CONTEXTS FORMATION \\ OF THE READER
}

\author{
Sabatha Catoia Dias \\ Programa de Pós-graduação em Linguística - UFSC \\ Mary Elizabeth Cerutti-Rizzatti \\ Universidade Federal de Santa Catarina
}

\begin{abstract}
Resumo
Este artigo resulta de pesquisa qualitativa interpretativista (MASON, 1998), empreendida na busca de responder à questão-problema: Como se caracteriza a ação docente em se tratando da articulação entre os universos "local" e "global" no tratamento da leitura na escola? Os participantes de pesquisa são oito professores de ensino fundamental de escolas públicas de municípios de Santa Catarina, convidados a relatar sua ação didático-pedagógica em se tratando da formação do leitor, com enfoque nas estratégias de articulação dos universos local e global (STREET, 2003; 2007). Concebendo que o trabalho com leitura precisa considerar conceitos-chave como gêneros discursivos (BAKHTIN, 2003 [1979]) e eventos e práticas de letramento (STREET, 1988; BARTON, 1994), dada a compreensão de que o ato de ler instaura-se em contextos interacionais, este estudo objetiva defender a articulação entre o local e o global no ensino da leitura, argumentando em favor da consideração das práticas de letramento para, com base nelas, mediar a ressignificação dessas práticas à luz das especificidades da macrocultura grafocêntrica das sociedades contemporâneas. A base teórica são estudos de Street (2003a; 2003b; 2007) sobre o diálogo entre o local e global nos eventos de letramento, e estudos de Bakhtin (2003 [1979]) sobre gêneros discursivos. A análise sinaliza uma ação docente consolidada em abordagens de leitura que parecem descuidar dos conceitos de gêneros discursivos e letramento e destituídas do zelo na articulação entre as dimensões local e global do letramento. Prevalecem encaminhamentos de leituras avulsas, a despeito de mais de duas décadas de discussões sobre a dimensão interacional dos usos da escrita.
\end{abstract}

Palavras-chave: Letramento. Gêneros discursivos. Universos local e global. Leitura.

\begin{abstract}
This article is the result of interpretative qualitative research (MASON, 1998), undertaken with the purpose of answering the following question-problem: What characterizes teacher action in regards to the articulation between the local and distant contexts in the teaching of reading at school? The research participants are eight teachers from elementary schools of Santa Catarina, who report their educationalpedagogical action in reference to the development of readers, with a focus on strategies that aim at articulating the local and distant contexts (STREET, 2003; 2007). Considering that the act of reading must consider key concepts such as discursive genres (BAKHTIN, 2003 [1979]) and literacy events and practices (STREET, 1988,
\end{abstract}


BARTON, 1994), given the understanding that the act of reading itself is introduced in interactional contexts, this study aims to defend the articulation between the local and distant contexts in the teaching of reading. In this vein, it favors literacy practices as a way to get them into the understanding of the specificities of the graphocentric macroculture of contemporary societies. The theoretical studies are Street (2003a; $2003 \mathrm{~b}$; 2007) on the dialogue between local and global levels in literacy events, and studies of Bakhtin (2003 [1979]) about genres. The analysis portrays a consolidated action in teaching approaches to reading that seem to neglect the concepts of discursive genres and literacy as well as the lack of articulation between the local dimension of literacy and the global dimension of literacy. Despite more than two decades of discussions about the interactional dimension of written language, still prevail readings loose forwards.

Keywords: Literacy. Discursive genre. Local and distant contexts. Reading.

\section{INTRODUÇÃO}

Desde o final da década de 1990, com a publicação dos Parâmetros Curriculares Nacionais de Língua Portuguesa (1998), a abordagem de leitura na escola vem sendo difundida à luz de concepções que priorizam os processos interacionais, no âmbito dos quais o ato de ler faz sentido. Também a partir da segunda metade dessa mesma década, ganharam espaço no Brasil teorizações sobre gêneros discursivos (BAKHTIN, 2003 [1979]) e letramento (STREET, 1984), conceitos essencialmente vinculados aos usos sociais da língua. Em se tratando desses dois conceitos, parecem ainda embrionários estudos que efetivamente os vinculem. Há sinalizações nesse rumo, a exemplo de Street (2009) e Oliveira (2009), posicionamentos que ganharam espaço no V Simpósio Internacional de Estudos de Gêneros do Discurso - SIGET - realizado em Caxias do Sul/RS no ano de 2009, com enfoque no ensino, e, ao que se anuncia, no VI SIGET, que terá lugar em Natal/RN no ano de 2011, cujo enfoque preliminar delineia-se na articulação entre gêneros e letramento.

Neste artigo, objetivamos advogar em favor da vinculação desses dois conceitos, dada a compreensão de que tanto os gêneros do discurso (BAKHTIN, 2003 [1979]) quanto os eventos de letramento (HEATH, 1982; STREET, 1988; BARTON, 1994) instituem interações sociais em que a língua escrita está presente, ainda que os gêneros não se restrinjam a essa modalidade da língua (movimento de ampliação que os estudos do letramento começam a agasalhar, processo que entendemos polêmico, mas que foge ao âmbito desta discussão). A vinculação desses dois conceitos ganha relevância neste estudo porque entendemos que a escola não pode mais ficar alheia à compreensão de que o ensino da língua também faz sentido fora dos muros escolares e não somente no interior deles; ou seja, não há mais como ensinar a língua escrita sem considerar a dimensão interacional a que ela se presta no dia-a-dia dos cidadãos.

Nessa discussão, importa que reconheçamos a inevitável artificialização dos gêneros discursivos e dos eventos de letramento no contexto intramuros da escola. Trata-se, em nossa compreensão, da artificialidade constitutiva de que trata Halté (2009 [1998]), afinal a escola, ao proceder a sua ação com base em gêneros discursivos e em eventos de letramento, tenta reconstruir contextos sociais que têm lugar fora dela; ou seja, tratase de reprodução e não de instauração dos processos tal qual se dão na sociedade. Essa, 
no entanto, é uma contingência que, em nosso entendimento, não desmerece a opção por conferir ao ensino da língua escrita a mais próxima ambientação que o justifica na sociedade na qual emergiu e na qual faz sentido, isso porque a escola é uma esfera da atividade humana com suas especificidades - e seus gêneros discursivos - e uma das especificidades é tematizar o mundo de modo a construir criticamente saberes sobre as diferentes esferas da atividade humana.

Nesse esforço, porém, parece haver uma questão adicional, foco de interesse deste artigo: as interações a que a língua escrita se presta não são uniformes e, como mostram os estudos sobre letramento, são situadas (BARTON, HAMILTON, IVANIC, 2000); afinal, tais interações são protagonizadas por sujeitos social e historicamente constituídos, o que delineia geografias e temporalidades nos usos sociais da escrita. Como a escola lida com essa dimensão local do letramento? Como empreende as relações entre essa mesma dimensão e a dimensão global, da macrocultura grafocêntrica? Discutir essas questões possivelmente implique discutir o papel efetivo da escola na formação do usuário da escrita: alguém capaz de se apropriar de usos da escrita em esferas distintas da sua, mas fazendo-o a partir da ressignificação dos sentidos atribuídos a essa mesma escrita em sua própria esfera, sem o que não parece haver ancoragens possíveis para o estabelecimento dos sentidos dos materiais escritos.

\section{LETRAMENTO E GÊNEROS: EM BUSCA DA ARTICULAÇÃO ENTRE OS UNIVERSOS LOCAL E GLOBAL NO ENSINO DA LEITURA}

Gee (2004) defende a concepção de que o domínio da escrita é um processo cultural, contrapondo-se à clássica dicotomização entre a condição natural da aquisição da oralidade e a condição artificial da aprendizagem da escrita. Para o autor, o domínio da escrita - particularizemos a leitura - não pode ser concebido a exemplo da artificialidade que caracteriza o aprendizado dos conhecimentos enciclopédicos em geral, tanto quanto não pode evidentemente ser tomado como equivalente à aquisição da oralidade - para a qual, segundo Dehaene (2007), os circuitos neurais estão especializados; já para a escrita, de acordo com esse mesmo neuropsicólogo, tais circuitos precisam ser reciclados.

Segundo Gee (2004), o domínio da escrita é um processo cultural, constituindo um tripé com os processos naturais (aquisição da fala) e artificiais (aprendizado de conhecimentos enciclopédicos). A condição de processo cultural confere à escrita a característica de ser aprendida na vivência social - também na escola, mas não apenas nela. Essa consideração, em nosso entendimento, é de substantiva importância para o ensino da leitura, uma vez que os aprendizes provêm de entornos socioculturais distintos; logo, trazem consigo distintas práticas de letramento, assim definidas por Street (2003a, p.8):

$\mathrm{O}$ conceito das práticas de letramento tenta tanto tratar dos eventos quanto dos padrões que tenham a ver com o letramento, procurando associá-los a algo mais amplo, de uma natureza cultural e social. Parte dessa amplificação tem a ver com a atenção dada ao fato de que trazemos para um evento de letramento conceitos, modelos sociais relacionados à natureza que o evento possa ter, os quais o fazem funcionar e que the dão significado. 
Essas práticas subjazem aos eventos de letramento de que os sujeitos participam, tais eventos, com base em Heath (1982), são entendidos como qualquer ocasião em que um texto escrito faça parte da natureza das interações dos participantes e de seus processos interpretativos. Segundo Street (2003a, p.7), porém,

[...] empregamos o conceito de evento de letramento de forma isolada, e ele permanece descritivo e - do ponto de vista antropológico, nada nos diz sobre a forma em que os significados são construídos. Caso observássemos esse evento de letramento como não-participantes e não tivéssemos sido treinados em suas convenções e em suas regras, teríamos dificuldade em acompanhar o que pudesse estar ocorrendo, como a maneira de trabalhar com o texto e como falar sobre ele. Nitidamente, existem convenções e suposições subjacentes implicadas no evento de letramento, que fazem com que ele funcione.

Essa subjacência de que trata o autor são as práticas de letramento. Para Hamilton (2000), as práticas são a base do iceberg de que os eventos são o topo; uma interessante metáfora que parece dar conta das implicações entre esses dois conceitos. A discussão dessas questões é relevante à medida que nos permite inferir que os sujeitos não compartilham práticas de letramento absolutamente universais e, por consequência, não participam de eventos de letramento idênticos. Esse compartilhamento e essa participação são situados (BARTON; HAMILTON; IVANIC, 2000); logo, socioculturalmente distintos, embora possa haver similitudes em maior ou menor grau.

Tais considerações, em convergência com Gee (2004), sinalizam para o fato de que os alunos chegam à escola com diferentes experiências sobre a leitura - dado que suas práticas de letramento sustentam a participação em eventos de letramento que têm sentido na ambientação cultural em que se inserem -; ou seja, os processos culturais de que participam lhes permitem o delineamento de experiências significativas à luz de seu entorno. Talvez pudéssemos mencionar aqui os conceitos de sociogênese e microgênese derivados de Vigotski (2000 [1984]). Pensar desse modo leva-nos a defender que a escola conheça as experiências de uso social da escrita - nesse caso, em especial, as experiências de leitura - dos alunos, de modo a valorizar suas práticas de letramento no processo de formação do leitor, trabalhando com gêneros discursivos que signifiquem para tais sujeitos, isto é, que façam parte de suas práticas de uso da língua escrita, sem contudo, deixar de trabalhar também com outros diferentes gêneros visando desenvolver as habilidades de leitura de tais sujeitos em vista da mobilidade social. Tal trabalho constituiria de fato um processo de ensino e aprendizagem significativo para o aluno, uma vez que levaria em conta suas habilidades implicadas no ato de ler.

No que respeita aos gêneros do discurso, importa referenciar Bakhtin (2003 [1979], p. 261 e 262):

Todos os diversos campos da atividade humana estão ligados ao uso da linguagem. Compreende-se perfeitamente que o caráter e as formas desse uso sejam tão multiformes quanto os campos da atividade humana [...] O emprego da língua efetua-se em forma de enunciados (orais e escritos) concretos e únicos, proferidos pelos integrantes desse ou daquele campo da atividade humana. Esses enunciados refletem as condições específicas e as finalidades de cada referido campo não só 
por seu conteúdo (temático) e pelo estilo da linguagem, ou seja, pela seleção de recursos lexicais, fraseológicos e gramaticais da língua, mas acima de tudo por sua construção composicional. [...] Evidentemente, cada enunciado particular é individual, mas cada campo de utilização da língua elabora seus tipos relativamente estáveis de enunciados, os quais denominamos gêneros do discurso.

Prossegue o autor:

A riqueza e a diversidade dos gêneros do discurso são infinitas porque são inesgotáveis as possibilidades da multiforme atividade humana e porque em cada campo dessa atividade é integral o repertório dos gêneros do discurso, que cresce e se diferencia à medida que se desenvolve e se complexifica determinado campo. (p. 262)

Entendendo que o ensino da leitura somente faz sentido se for tomado à luz das finalidades que a leitura tem no dia-a-dia dos cidadãos, importa a defesa de que tal ensino precisa se pautar na diversidade dos gêneros do discurso que caracterizam a interação do homem em atividade social; do contrário, a artificialidade constitutiva (HALTÉ, 2009 [1998]) que caracteriza a ação escolar será não mais que mero artificialismo.

A inadiável opção pelo trabalho com gêneros do discurso que, em sua constitutividade, caracterizam a interação humana, é, por lógica, isonômica à consideração dos eventos de letramento e das práticas de letramento dos cidadãos histórica e socialmente concebidos; ou seja, o professor tem, diante de si, sujeitos com experiências flagrantemente mapeáveis acerca dos usos sociais da escrita. Cabe-lhe, pois, conhecer as práticas de letramento desses sujeitos, o que remete aos gêneros discursivos - para o nosso foco, os gêneros escritos - que constituem interações humanas nos entornos de que tais alunos fazem parte. Eis os letramentos situados (BARTON; HAMILTON; IVANIC, 2000).

Advogar em favor do respeito aos letramentos situados coloca em questão as relações topicalizadas neste estudo entre os universos local e global. Brandt e Clinton (2002) entendem que a preocupação em tomar os letramentos como situados enfatiza demasiadamente o caráter local das práticas de letramento que acaba perdendo a dimensão mais ampla dos letramentos, a dimensão global. Para as autoras, tais estudos exageram no poder conferido aos letramentos locais, na medida em que as práticas de letramento não são inventadas por aqueles que as vivenciam. Street (2003b) responde a essas críticas fazendo menção à hibridização dos letramentos na relação local $x$ global. Segundo o autor, os usos sociais da escrita que têm lugar no espectro da macrocultura não chegam aos universos locais impunes; sofrem algum tipo de reverberação, de hibridização.

Eis, aqui, a questão axial deste estudo: Não será papel da escola - conhecendo as práticas e os eventos de letramento que caracterizam a inserção sociocultural dos alunos e, por consequência, os gêneros do discurso constitutivos das interações ali estabelecidas - ressignificar tais práticas de letramento, de modo que esses alunos possam vivenciar novos eventos de letramento, constituindo interações por meio de gêneros do discurso que lhe são e que não lhes sejam familiares, objetivando ampliar as 
possibilidades de trânsito em esferas da atividade humana a que até então não têm acesso, facultando, assim, habilidades aos alunos referentes à transformação das demandas sociais? $O$ ensino da leitura não teria de ter esse objetivo, dado que a subjacência dessa discussão traz consigo a perspectiva de articulação dos letramentos locais com os letramentos globais, o que, não raro representa a articulação de letramentos vernaculares com letramentos institucionais (HAMILTON, 2000)? O papel da escola, em se tratando do ensino da leitura, não é facultar ao sujeito, histórica e socialmente concebido, a possibilidade de ampliar suas condições de movimentação em esferas da atividade humana distintas das suas e de modificá-las? Se assim o for, a articulação entre o universo local - a microcultura de que faz parte o aluno constituída, dentre outros elementos, por diferentes gêneros discursivos - e o universo global - a macrocultura grafocêntrica (composta por tantos outros gêneros com os quais diversos alunos não têm familiarização) - tende a se revelar estratégia nodal para uma ação escolar consequente.

\section{A AÇÃO DIDÁTICO-PEDAGÓGICA DE PROFESSORES DE LÍNGUA PORTUGUESA E A FORMAÇÃO DO LEITOR: UMA DISCUSSÃO SOBRE PROTOTIPICIDADE NA ATUAÇÃO DOCENTE.}

Este estudo constitui uma pesquisa qualitativa, de cunho interpretativista (MASON, 1998), e busca responder à seguinte questão-problema: Como se caracteriza a ação docente em se tratando da articulação entre os universos "local" e "global" no tratamento da leitura na escola?. Os participantes de pesquisa são oito professores de Língua Portuguesa de escolas públicas de municípios da metade sul de Santa Catarina, entrevistados por ocasião de sua participação em curso de especialização no campo da metodologia de Língua Portuguesa.

Os professores foram convidados a discorrer sobre suas atividades em aulas de leitura nas séries em que atuavam - quarto a nono ano do ensino fundamental. Pedimos a eles que descrevessem as estratégias de que se valem para mediar a formação do leitor, especificando o tipo de material escrito que levam para as aulas e detalhando a abordagem que imprimem a tais materiais. A geração de dados deu-se no ano de 2007 parte do corpus foi tratado em Cerutti-Rizzatti (2008) -, e as falas foram gravadas e transcritas. Muitos dos participantes de pesquisa repassaram a nós materiais a que faziam alusão, permitindo-nos empreender um recorte de pesquisa documental de natureza complementar. Codificaremos os participantes com base na ordem alfabética dos sobrenomes - letra maiúscula - e com base na série de atuação - número que segue a letra ${ }^{1}$.

A primeira questão que entendemos de necessária focalização são os gêneros do discurso que prevalecem na ação didático-pedagógica desses professores: conto, lenda e fábula; raras incidências de reportagem assinada e de propaganda comercial. Possivelmente nem possamos tratar desses materiais prevalecentes - conto, lenda e fábula - sob a perspectiva teórica bakhtiniana, dado que não constituem gêneros efetivamente, mas excertos de textos, fragmentos de contos clássicos infanto-juvenis,

\footnotetext{
${ }^{1}$ Ainda que Mason (1998) recomende não codificar desse modo, optamos pelo risco de o fazer em nome da não identificação dos sujeitos e da indisposição para o uso de nomes fictícios.
} 
lendas sumarizadas e fábulas retextualizadas. Os materiais com os quais tivemos contato não instauram interações sociais em situações naturalísticas de convivência humana - e, por isso, entendemos não representarem de forma efetiva gêneros discursivos - pelo fato de que constituem versões adaptadas para finalidades didático-pedagógicas. Nesses casos, a artificialidade constitutiva de que trata Halté (2009 [1998]) revela-se, a exemplo do que mencionamos anteriormente, mero artificialismo: materiais produzidos para atividade em classe. Sobre isso, enuncia-se D5:

(1) Às vezes, sinto que os textos que levo para meus alunos de $5^{a}$ série estão incompletos. Um dia, lemos um texto do livro didático que era um pedaço do livrinho "No reino perdido do Beleléu". O texto não fazia sentido. No ano seguinte, minha filha ganhou este livrinho de presente, dai entendi o que era aquele pedaço que o livro didático trazia. (D5, transcrição 29)

A eventual consciência acerca das limitações do material didático utilizado em classe, no entanto, não parece ser suficientemente motivadora para dar conta de mudanças na ação docente nesse grupo. F7, questionada sobre essas limitações, enuncia:

(2) A gente sabe que há problemas, não só nos livros didáticos, mas nos textos que usamos de um ano para outro. Não dá para dar o livrinho todo para os alunos, então temos que dar fragmentos. A lenda do "Negrinho do Pastoreio", por exemplo, eu sempre dou uma parte porque o texto é muito extenso, e os alunos reclamam. (F7, transcrição 12)

Enunciações como essa parecem assumir um comportamento como inexorável: o que transita na escola são materiais escritos cuja leitura tem finalidade escolar tão-somente. Os usos sociais da escrita, tal qual concebidos pelos estudos de letramento (STREET, 1984; 2003a) e por Bakhtin (2003 [1979]), ainda que implicitados em referenciais institucionais, como PCN's (1998), ecoam em horizontes distantes em se tratando das experiências desse grupo. Dessa forma, o texto, por ser fragmentado, não assume seu papel de unidade interacional, de texto-enunciado (concebido como materialização dos usos da língua nas interações instituídas por meio de gêneros). Consequência é a ausência de co-construção dos sentidos dos textos por parte dos alunos. Também a busca pela articulação dos universos local e global mostra-se uma ambição de conotação utópica diante de enunciações como de R8:

(3) Se eu conheço as experiências de leitura dos alunos? Acho que sim, porque há quinze anos eu trabalho com oitava série, acho que posso dizer que conheço o tipo de textos que esses alunos leem em casa. (R8. transcrição 4)

Objetivando entender melhor essa consideração de R8, perguntamos à professora se $\mathrm{o}$ fato de ter vasta experiência numa seriação escolar poderia ser sinônimo de conhecer as práticas de letramento que caracterizam os alunos que recebe a cada ano, e obtivemos como resposta a consideração de que os alunos distinguem-se por faixas etárias, o que permite inferir o tipo de experiências de leitura que os caracteriza. Compreensões como essa requerem as considerações de Barton, Hamilton e Ivanic (2000) sobre a natureza situada das práticas de letramento. A inserção em faixas etárias, ainda que 
historicamente legitimada, tende a nortear olhares voltados para dimensões de natureza biológica e maturacional em detrimento de olhares de natureza sociocultural e histórica.

Nossa atenção para articulações entre os universos local e global (STREET, 2003a; 2003b) fez-nos persistir na abordagem do tema, perguntando aos participantes da pesquisa que gêneros discursivos entendiam ser novidades para os seus alunos e como concebiam a abordagem de tais gêneros. Várias respostas nos levaram à compreensão da ausência de distinções entre saberes locais e saberes globais. Parece grassar, nesse grupo, a adoção de comportamentos prototípicos, ou seja, a seleção de gêneros discursivos dados a priori como necessariamente endereçados à seriação escolar com que trabalham, independentemente de quem sejam os alunos e com que práticas de letramento convivam, ou, ainda, um processo de seleção pautado na organização do tempo do professor, tal como mostram as enunciações a seguir.

(4) Nós escolhemos este ano, na escola, o conto infanto-juvenil para trabalhar com as sextas séries. No ano passado, nós trabalhamos o conto com as quintas; nesse ano, resolvemos trabalhar com as sextas porque os alunos tiveram dificuldades na leitura desse tipo de texto. Fizemos vários projetos com contos infanto-juvenis, e os alunos gostaram muito. (B6, transcrição 20)

(5) Eu gosto de escolher os textos todos no início do ano. Ao final de cada ano, faço uma avaliação daquilo que funcionou e daquilo que não funcionou; então, separo os textos para o ano seguinte. Como uso o livro didático apenas para complementar meu trabalho, preciso de muitos textos e, como não tenho tempo ao longo do ano, separo os materiais nas férias. (S4, transcrição 3)

Mais uma vez, elicia-se o artificialismo do processo didático-pedagógico. Desconsiderar o perfil dos alunos para a seleção de textos de diferentes gêneros, em nosso entendimento, tem como consequência o desenvolvimento de um trabalho de leitura comprometido em sua significação, uma vez que não é voltado ao público em questão e com uma tendência a apresentar resultados inadequados no que concerne à implementação de habilidades referentes ao ato de ler e à co-construção de sentidos. Além disso, a prática de selecionar gêneros para cada série escolar resulta, em boa parte das vezes, na objetificação dos gêneros discursivos, na inobservância de que o gênero deve ser utilizado como meio, como megainstrumento (SCHNEWULUY, 2004) para o trabalho da língua em uso.

Paralelamente a essa organização a priori, conversamos com os participantes sobre a abordagem que costumam imprimir aos materiais encaminhados para leitura, e novamente a prototipicidade se revelou - entendida, aqui, como comportamentos cristalizados nas práticas de ensino da língua materna. Os depoimentos dos professores e a pesquisa documental que pudemos realizar sugerem a prevalência de abordagens focadas na localização de informações e na emissão de opiniões, descurando de habilidades que implicam construção dos sentidos do texto com base em inferenciações, associações, leitura de implícitos, ativação de esquemas cognitivos, evocação de conhecimento prévio etc. (KINTCH, 1998; VAN DIJK; KINTCH, 1983), habilidades essas que, associadas ao aspecto interacional do ato de ler, fundamentam o processo de leitura. Dentre os 38 materiais - dezessete fragmentos de contos infanto-juvenis; nove 
fábulas; sete lendas; três reportagens assinadas e duas propagandas comerciais - a que tivemos acesso, acompanhados das mais de cem questões reunindo todos os textos, pudemos observar que apenas treze dentre as 124 perguntas, requeriam habilidades de inferenciação dos leitores; todas as demais tinham como mote o mapeamento de informações ou a emissão de opiniões.

Contos infanto-juvenis, lendas e fábulas, dada sua condição de gêneros discursivos representativos, em tese, de construtos culturais de relativa universalidade, já que permeiam diferentes ambientações socioculturais e econômicas de diversas populações, parecem dar conta de universos globais de letramento. Essa, porém, não é uma caracterização que possamos estabelecer a priori, dado que a relação local X global, em nosso entendimento e com base em Street (2003a; 2003b), somente pode ser delineada a partir de sujeitos social e historicamente situados, daí a importância de o professor conhecer quem são seus alunos, de que ambientações provêm, como se caracteriza sua microcultura - entendida, aqui, com base em Lahire (2008 [1995]), como o espaço correspondente à família, igreja, vizinhança -, para, então, organizar uma ação didáticopedagógica, ancorada teoricamente, cujo mote seja a valorização das práticas e eventos de letramento (HEATH, 1982; STREET, 1988; BARTON, 1994) que caracterizam a formação cultural desses alunos, e, a partir dessas práticas e eventos, facultar a tais alunos a ampliação de suas vivências de leitura, de modo a habilitarem-se para transitar em outras esferas sociais, de natureza mais global e que requeiram deles novas competências como leitores.

\section{CONSIDERAÇÕES FINAIS}

A formação do leitor, em nosso entendimento, implica uma postura desafiadora do professor na contemporaneidade, sobretudo à luz das teorizações sobre gêneros do discurso e letramento. A escrita, na escola, precisa significar para os sujeitos em formação, sob pena de o artificialismo constitutivo da escolarização (HALTÉ, 2008 [1998]) redundar no esvaziamento de sentidos, tal qual supomos acontecer na prática pedagógica de muitos de nós, professores de língua materna. Comportamentos prototípicos, cristalizados no dia-a-dia do fazer em língua portuguesa - a exemplo de definições a priori em que abordagens uniformizadoras prevalecem - ameaçam novas posturas, coibindo-as em grande medida.

Tornar significativo o processo de formação de leitores habilidosos, em nossa compreensão, requer o conhecimento das práticas de letramento (STREET, 1988; BARTON, 1994) dos alunos com os quais lidamos cotidianamente, de modo a entender a dimensão situada do letramento (BARTON; HAMILTON; IVANIC, 2000) e a necessidade de articulação desses letramentos locais com os letramentos globais (STREET, 2003b), isso se nossos objetivos, de fato, contemplarem a ressignificação das experiências dos sujeitos com a leitura, em busca de novos domínios, da possibilidade de construir sentidos em gêneros com os quais tais alunos não estejam familiarizados, favorecendo a hibridização entre eventos de letramento locais e eventos de letramento globais, do que depende, sob vários aspectos, a possibilidade de o sujeito transitar em entornos sociais distintos do seu, assegurando a si próprio uma mobilidade social que lhe faculte novos espaços de cidadania. 


\section{REFERÊNCIAS}

BAKHTIN, Mikhail. Os gêneros do discurso. In: Estética da criação verbal. Tradução de Paulo Bezerra. 4. ed. São Paulo: Martins Fontes, 2003 [1979]. p. 261-306.

BARTON, David. Literacy - an introduction to the ecology of written language. Cambridge/USA: Brackwell, 1994.

.; HAMILTON, M.; IVANIC, R. Situated literacies. London: Routledge, 2000.

BRANDT, Deborah; CLINTON, Katie. Limits of the local: expanding perspectives on literacy as a social practice. Journal of Literacy Research, v. 34, n.3, p. 337-356, 2002.

BRASIL. Parâmetros Curriculares da Educação Nacional - Língua Portuguesa. Secretaria de Educação Fundamental. Brasília/DF, 1998.

CERUTTI-RIZZATTI, Mary Elizabeth. Implicações metodológicas do processo de formação do leitor e do produtor de textos na escola. Educação em Revista. Belo Horizonte, n. 47, p. 55-82, 2008.

DEHAENE, S. Les neurones de la lecture. Paris: Odile Jacob, 2007.

GEE, P.J. Situated language and learning: a critique of traditional schooling. Londres: Routledge, 2004.

HALTÉ, Jean-François. O espaço didático e a transposição. In: Fórum Lingüístico, Florianópolis, p. 117-139, jul./dez. 2008 [1998].

HAMILTON, Mary. Sustainable literacies and the ecology of lifelong learning, London, 2000.

HAMILTON, Mary. Expanding the new literacy studies: using photographs to explore literacy as social practice. In: BARTON, David; HAMILTON, Mary; IVANIC, Roz (Org.) Situated literacies. London: Routledge, 2000.

HEATH, S. B. What no bedtime story means: narrative skills at home and school. Language in Society, 1982.

KINTCH, A. A paradigm for cognition. Cambridge: Cambridge University Press, 1998

LAHIRE, B. O sucesso escolar nos meios populares. São Paulo: Ática, 2008 [1995].

MASON, Jennifer. Qualitative researching. London: Sage publications, 1998.

OLIVEIRA, Maria do Socorro. Gêneros textuais e letramento. Anais do V SIGET. Caxias do Sul, 2008. 
SCHNEUWLY, Bernard. Gêneros e tipos de discurso: considerações psicológicas e ontogenéticas. In: SCHNEUWLY, Bernard; DOLZ, Joaquim. Gêneros orais e escritos na escola. Campinas/SP: Mercado das Letras, 2004. p. 21-40.

STREET, Brian. Academic Literacies approaches to Genre? Anais do V SIGET. Caxias do Sul, 2008

. Literacy: an advanced resource book. London: Routledge, 2007.

. Abordagens alternativas ao letramento e desenvolvimento. Teleconferência

Brasil sobre o letramento, outubro de 2003a.

. What's "new" in New Litearcy Studies? Critical approaches to literacy in theory and practice. Current Inssues in Comparative Education 5 (2), maio de 2003 b.

Practices and Literacy Myths. In : SALJO,R (Ed.) The Written World: studies in literate thought and action. Springer-Verlag: Berlim/Nova Iorque, 1988

Literacy in theory and practice. Cambridge: CUP, 1984.

Van DIJK, Teun. A.; KINTCH, A. A caminho de um modelo estratégico de processamento do discurso. In: Van DIJK, Teun, Cognição, discurso e interação. 6. ed. São Paulo: Contexto, 2004. p. 9-35.

VIGOTSKI, L. A formação social da mente. São Paulo: Martins Fontes, 2000 [1984]. 